\title{
Paricalcitol for CKD-MBD Associated with Secondary Hyper- parathyroidism: A Case Series Focus on TRAP5b, b-ALP, and DKK-1
}

\author{
Budi Suprapti $^{*}$, Frenky Hartono ${ }^{1}$, Muhammad Iqbal ${ }^{1}$, Muh Isnaini Zuhri ${ }^{1}$ and $^{\text {Aditiawardana }}{ }^{2}$ \\ 1. Department of Clinical Pharmacy, Faculty of Pharmacy, Universitas Airlangga, Campus C Jl. Mulyorejo, 10115, \\ Surabaya, Indonesia \\ 2. Department of Nephrology, Faculty of Medicine, Dr. Soetomo Hospital, Jl. Mayjen Prof. Dr. Moestopo No.6-8, \\ Airlangga, 60286, Surabaya, Indonesia
}

\author{
Info Article \\ Submitted: 6-12-2018 \\ Revised: 9-3-2019 \\ Accepted: $13-3-2019$ \\ *Corresponding author \\ Budi Suprapti \\ Email: \\ budi-s@ff.unair.ac.id
}

\begin{abstract}
Chronic kidney disease (CKD) lead to secondary hyperparathyroidism (sHPT) that caused by phosphate retention and hypocalcemia. This condition known as mineral and bone disorder (CKD-MBD). The increase in parathyroid hormone would increase bone turnover that result in an increased risk of bone fractures, and vascular calcification. These will increase the levels of tartrate-resistant acid phosphatase 5b (TRAP5b), and bone-specific alkaline phosphatase (b-ALP), which is a marker of bone turnover, and also dickkopfrelated protein 1 (DKK-1), which is an inhibitor of the Wnt pathway. Secondary hyperparathyroidism in CKD also caused by calcitriol deficiency. Paricalcitol is a synthetic calcitrol analogue used to reduce parathyroid hormone (iPTH) with minimal calcemic and phosphatemic activity. Vitamin D receptor activation by paricalcitol will decrease TRAP5b, b-ALP, and DKK1. In this study we reported 9 cases of CKD-MBD with Hemodialysis (HD) and associated with sHPT. Four of nine cases received $5 \mu \mathrm{g}$ paricalcitol every HD (twice a week) while the others five is not. Level of iPTH, phosphate, calcium, TRAP5b, b-ALP, and DKK-1 were measured before initiation of study and after three months treatment. According to this study, the paricalcol administration suppresses the increase in iPTH level, bone turnover and vascular calcification showed by decreasing or supresses the increase b-ALP, TRAP5b, DKK-1 leves without increasing calcium and phosphate levels.

Keywords: secondary hyperparathyroidism, paricalcitol, TRAP5b, b-ALP, DKK-1.
\end{abstract}

\section{INTRODUCTION}

Deranged mineral metabolism in patient with chronic kidney disease (CKD) result not only in bone disease, but a higher risk of cardiovascular disase and reduce survival, through the developement of vascular calcification, which is known as CKD-Mineral and Bone Disorder (CKDMBD). CKD-MBD is a systemic condition that manifests as abnormalities in parathyroid hormone (PTH), calcium, phosphorus and vitamin D; bone abnormalities and extraskeletal calcification which shown by Tartrate-resistant acid phosphatase $5 \mathrm{~b}$ (TRAP-5b), and bone-specific alkaline phosphatase (b-ALP) (Fukugawa, et al., 2013). In patients with CKD-MBD a calcitriol deficiency leads to the development of secondary HPT (sHPT) both by direct and indirect effects (Llach, et al., 1998). Beside that, calcitriol deficiency also reduces activity of vitamin D receptor that suppressing dickkopf-related protein 1 (DKK-1) expression (Cianferotti, and Demay, 2007).

Paricalcitol is an analogue of calcitriol that suppresses iPTH secretion while having only minor effects on serum level of calcium and phosphate (Lacy, et al., 2011). Levels of iPTH have a positive correlation with bone turnover rate (ie, both resorption and formation) and vascular calcification (Jilka et al., 2010 and Shetty et al., 2016). So that Paricalcitol therapy in CKD-MBD effectively decreases osteoblast activity (b-ALP level) (Coyne et al., 2013), serum TRAP-5b as a marker of bone resorption and DKK-1 as an inhibitor of Wnt pathway that have a role in vascular calcification. The aim of the study was to analyze changes of serum levels calcium, phosphate, intact parathyroid hormone (iPTH), 
Table I. Baseline characteristics of the nine cases

\begin{tabular}{lcccccc}
\hline \multicolumn{1}{c}{ Patient } & & Sex & Age (yr) & Etiology of ESRD & $\begin{array}{c}\text { Body surface } \\
\text { area (m²) }\end{array}$ & $\begin{array}{c}\text { HD Duration } \\
\text { (Months) }\end{array}$ \\
\hline Paricalcitol & 1 & Male & 43 & NDN & 1.84 & 130 \\
& 2 & Male & 70 & DN & 1.81 & 68 \\
& 3 & Male & 62 & NDN & 1.92 & 18 \\
Without & 4 & Female & 64 & NDN & 1.45 & 33 \\
Paricalcitol & 5 & Male & 50 & DN & 1.89 & 42 \\
& 6 & Male & 51 & NDN & 2.07 & 54 \\
& 7 & Female & 75 & NDN & 1.52 & 19 \\
& 8 & Male & 55 & DN & 2.14 & 19 \\
\hline
\end{tabular}

DN: Diabetic nephropathy; NDN: Non-diabetic nephropathy

TRAP5b, b-ALP, and DKK-1 on CKD-MBD patient with SHPT who received and without paricalcitol for three months.

\section{MATERIAL AND METHODS}

This study was cohort prospective observational to evaluate the effect of paricalcitol in CKD-MBD associated with secondary hyperparathyroidism. The inclusion criteria were hemodialysis patient with end stage renal disease and MBD, age more than 18 years, iPTH serum concentration $\geq 150 \mathrm{pg} / \mathrm{mL}$, calcium serum concentration $\leq 11 \mathrm{mg} / \mathrm{Dl}$, phosphate serum concentration $\leq 10.2 \mathrm{mg} / \mathrm{dL}$, with or without paricalcitol therapy. The exclusion criteria was patient with severe liver injury with ChildPugh Score 10-15. Blood serum withdrawn twice, first before paricalcitol therapy and the second was 3 month after paricalcitol therapy. Analyzed was done for the serum concentration of calcium, phosphate, PTH, b-ALP, TRAP5b, and DKK-1.

\section{Case ilustration}

In this study we present nine patients who developed CKD-MBD with hemodialysis (HD) at a hospital in Surabaya City, Indonesia. The patients grouped into 2 groups, first group contain 4 patients with paricalcitol therapy and second group contain 5 patients without paricalcitol therapy. Baseline characteristics of nine patients (Table I). Serum level of calcium, phosphate, iPTH, TRAP-5b, b-ALP and DKK-1 were measured twice, before initiation of study $\left(\mathrm{t}_{0}\right)$ and after 3 months $\left(t_{1}\right)$. Result of paricalcitol group (Table II) and without paricalcitol group (Table III).

Besides, the correlation test was also performed among serum level of iPTH with TRAP5b, b-ALP, DKK-1 and the correlation of
TRAP5 $b$ and $b$-ALP, TRAP5b and DKK-1, also b-ALP and DKK-1.

Case 1: A 45-year-old man with hypertension, end stage renal disease (ESRD). Level of calcium, phosphate, iPTH, b-ALP, TRAP5B, and DKK-1 decreased after 3 months of paricalcitol. Another therapy was also given to this patient such as risedronate, and lanthanum carbonate; Case 2: A 70-year-old man with diabetic nephropathy, hypertension, ESRD. Level of calcium, iPTH, b-ALP, and DKK-1 decreased but level of phosphate, and TRAP5b increased after 3 months of paricalcitol. Another therapy was also given to this patient such as lanthanum carbonate; Case 3: A 62-year-old man with hypertension, ESRD. Level of b-ALP, and TRAP5B decreased but level of calcium, phosphate, iPTH, and DKK-1 increased after 3 months of paricalcitol. During treatment level of uric acid also increased from $5.54 \mathrm{mg} / \mathrm{dL}$ to $7.31 \mathrm{mg} / \mathrm{dL}$. Another therapy was also given to this patient such as calcium acetate; Case 4: A 64-year-old woman with hypertension, ESRD. Level of calcium, b-ALP, and DKK-1 decreased but level of phosphate, iPTH, and TRAP $5 b$ increased after 3 months of paricalcitol. During treatment level of uric acid also increased from $4.83 \mathrm{mg} / \mathrm{dL}$ to $6.78 \mathrm{mg} / \mathrm{dL}$. Another therapy was also given to this patient such as risedronate, and calcium acetate; Case 5: A 50-year-old man with diabetic nephropathy, hypertension, end ESRD. Patient has history of GERD with treatment of cisapride. Level of calcium, and DKK-1 decreased but level of iPTH, b-ALP, and TRAP5b increased without change on phosphate level after 3 months. Level of uric acid also increased from $6.75 \mathrm{mg} / \mathrm{dL}$ to $8.54 \mathrm{mg} / \mathrm{dL}$; Case 6: A 51 -year-old man with hypertension, ESRD. Level of calcium, iPTH, b-ALP, TRAP5b, and DKK-1 increased but level of phosphate decreased after 3 months. Another 
Table II Serum levels and changes of calcium, phosphate, iPTH, in paricalcitol group

\begin{tabular}{cccccccccc}
\hline \multirow{2}{*}{ Patient } & \multicolumn{3}{c}{ Calcium (mg/dL) } & \multicolumn{4}{c}{ Phosphate (mg/dL) } & \multicolumn{3}{c}{ iPTH (pg/mL) } \\
\cline { 2 - 10 } & $\mathbf{t}_{\mathbf{0}}$ & $\mathbf{t}_{\mathbf{1}}$ & $\boldsymbol{\Delta} \mathbf{t}_{\mathbf{1}-\mathbf{t}_{\mathbf{0}}}$ & $\mathbf{t}_{\mathbf{0}}$ & $\mathbf{t}_{\mathbf{1}}$ & $\boldsymbol{\Delta} \mathbf{t}_{\mathbf{1}} \mathbf{t}_{\mathbf{0}}$ & $\mathbf{t}_{\mathbf{0}}$ & $\mathbf{t}_{\mathbf{1}}$ & $\boldsymbol{\Delta} \mathbf{t}_{\mathbf{1}}-\mathbf{t}_{\mathbf{0}}$ \\
\hline 1 & 9.5 & 9.2 & -0.3 & 5.84 & 5.74 & -0.10 & 627.3 & 578.7 & -48.6 \\
2 & 10.8 & 10.3 & -0.5 & 6.21 & 6.64 & 0.43 & 544.4 & 378.4 & -166.0 \\
3 & 8.0 & 8.1 & 0.1 & 4.94 & 5.69 & 0.75 & 751.8 & 816.8 & 65.0 \\
4 & 9.4 & 8.3 & -1.1 & 2.55 & 4.15 & 1.60 & 542.4 & 1165.0 & 622.6 \\
Mean & 9.4 & 9.0 & -0.4 & 4.88 & 5.56 & 0.67 & 616.5 & 734.7 & 118.2 \\
SD & 1.1 & 1.0 & 0.5 & 1.65 & 1.03 & 0.71 & 98.5 & 338.2 & 349.2 \\
\hline
\end{tabular}

therapy was also given to this patient such as calcium acetate; Case 7: A 75-year-old woman with hypertension, ESRD. Level of calcium, phosphate, and $b$-ALP decreased but level of iPTH, TRAP5 $b$, and DKK-1 increased after 3 months. Another therapy was also given to this patient such as risedronate, and calcium acetate; Case 8: A 55-year-old man with diabetic nephropathy, hypertension, ESRD. Level of phosphate, iPTH, b-ALP, TRAP5B, and DKK1 increased but level of calcium decreased after 3 months; Case 9: A 38-year-old woman with diabetic nephropathy, hypertension, ESRD. Level of iPTH, bALP, TRAP5B, and DKK-1 increased but level of calcium and phosphate decreased after 3 months. Another therapy was also given to this patient such as calcium acetate.

\section{RESULT AND DISCUSSION}

Chronic Kidney Disease-Mineral Bone Disorder (CKD-MBD) is a systemic disorder of mineral and bone metabolism due to CKD manifested by abnormalities of calcium, phosphorus, PTH, or vitamin D metabolism, abnormalities in bone turnover, mineralization, volume, linear growth, or strength, vascular or other soft tissue calcification (KDIGO, 2009). As kidney function continues to decline and the GFR falls less than $30 \mathrm{~mL} / \mathrm{min} / 1.73 \mathrm{~m}^{2}\left(0.29 \mathrm{~mL} / \mathrm{s} / \mathrm{m}^{2}\right)$, phosphorus excretion continues to decrease and calcitriol production decreases, causing PTH levels to begin to rise significantly, leading to SHPT (Dipiro, 2013).

The excessive production of PTH leads to hyperplasia of the parathyroid glands, which decreases the sensitivity of the parathyroid glands to serum calcium levels and calcitriol feedback, further promoting sHPT. The most dramatic consequence of SHPT is alterations in bone turnover and the development of renal osteodystrophy (ROD) (Dipiro, 2013). Paricalcitol is a synthetic vitamin $\mathrm{D}$ analog which binds to and activates the vitamin D receptors (VDR) in kidney, parathyroid gland, intestine and bone, thus reducing PTH levels and improving calcium and phosphate homeostasis (Lacy, et al., 2011).

Level of iPTH in circulation reflects bone turnover, a better correlation of iPTH with bone turnover markers especially TRAP5b and b-ALP has been reported (Fukugawa, et al., 2013). DKK-1 change in CKD is not only influenced by iPTH but also by inflammation cytokines such as IL-6 and TNF- $\alpha$ (Lee and Kalluri, 2010; Yao et al., 2011; Yeremenko et al, 2015). Administration of paricalcitol could reduce iPTH level which affected decline bone turnover marker and inhibit Wnt pathway (He et al., 2011; Cozzolino et al., 2014).

Table II, III, IV and V showed that before initiation of study $\left(\mathrm{t}_{0}\right)$ serum levels of calcium and phosphate were in normal range, while serum levels of iPTH, TRAP5b, b-ALP, and DKK-1 increased from normal range. This is in accordance with the pathophysiology of CKD-MBD. There were a homeostatic between calcium and phosphate by increasing PTH that will increase the impact on bone turnover, and also decreasement of VDR activity. Those caused increasement of TRAP5b, b-ALP and DKK-1 (Fukugawa et al., 2013; Cianferotti and Demay, 2007; Saliba and El-Haddad, 2009).

Generally, after three month from initiation of study there were no changes on serum levels of calcium and phosphate in 2 groups, while in paricalcitol group iPTH and TRAP5b increased although not as much as in without paricalcitol group. b-ALP and DKK-1 increased in without paricalcitol group while decreased in paricalcitol group.

The selectivity of paricalcitol in VDR has a little effect on absorption of calcium and phosphate in intestine (Lacy et al., 2011; Slatopolsky et al., 2003). Other factors which affected levels of 
Table III Serum levels and changes of b-ALP, TRAP5B, and DKK-1 in paricalcitol group

\begin{tabular}{cccccccccc}
\hline \multirow{2}{*}{ Patient } & \multicolumn{3}{c}{$\mathbf{b}-\mathbf{A L P}(\mathbf{U} / \mathbf{L})$} & \multicolumn{3}{c}{ TRAP5B (U/L) } & \multicolumn{3}{c}{ DKK-1 (pg/mL) } \\
\cline { 2 - 10 } & $\mathbf{t}_{\mathbf{0}}$ & $\mathbf{t}_{\mathbf{1}}$ & $\boldsymbol{\Delta} \mathbf{t}_{\mathbf{1}-\mathbf{t}_{\mathbf{0}}}$ & $\mathbf{t}_{\mathbf{0}}$ & $\mathbf{t}_{\mathbf{1}}$ & $\boldsymbol{\Delta} \mathbf{t}_{\mathbf{1}-\mathbf{t}_{\mathbf{0}}}$ & $\mathbf{t}_{\mathbf{0}}$ & $\mathbf{t}_{\mathbf{1}}$ & $\boldsymbol{\Delta} \mathbf{t}_{\mathbf{1}}-\mathbf{t}_{\mathbf{0}}$ \\
\hline 1 & 35.3 & 29.1 & -6.2 & 7.3 & 8.2 & 0.9 & 2871 & 2275 & -596 \\
2 & 22.6 & 21.0 & -1.6 & 4.9 & 5.0 & 0.1 & 679 & 666 & -13 \\
3 & 31.7 & 23.3 & -8.4 & 6.8 & 6.6 & -0.2 & 1444 & 2096 & 652 \\
4 & 92.1 & 89.7 & -2.4 & 4.9 & 8.1 & 3.2 & 2239 & 1302 & -937 \\
Mean & 45.4 & 40.8 & -4.6 & 6.0 & 7.0 & 1.0 & 1808 & 1585 & -224 \\
SD & 31.6 & 32.8 & 3.2 & 1.2 & 1.5 & 1.5 & 953 & 744 & 697 \\
\hline
\end{tabular}

iPTH: Intact parathyroid hormone;TRAP5b: Tartrate-resistant-acid-phosphatase 5b; b-ALP: Bone specific alkaline phosphatase; DKK1: Dickkopf-related protein $1 ; t_{0}$ : time before initiation of study; $t_{1}: 3$ months after initiation of study; $\Delta t_{1}-t_{0}$ : Change from $t_{0}$ to $t_{1}$

Table IV Serum levels and changes of calcium, phosphate, iPTH in without-paricalcitol group

\begin{tabular}{cccccccccc}
\hline \multirow{2}{*}{ Patient } & \multicolumn{3}{c}{ Calcium (mg/dL) } & \multicolumn{3}{c}{ Phosphate (mg/dL) } & \multicolumn{3}{c}{ iPTH (pg/mL) } \\
\cline { 2 - 10 } & $\mathbf{t}_{\mathbf{0}}$ & $\mathbf{t}_{\mathbf{1}}$ & $\boldsymbol{\Delta} \mathbf{t}_{\mathbf{1}-\mathbf{t}_{\mathbf{0}}}$ & $\mathbf{t}_{\mathbf{0}}$ & $\mathbf{t}_{\mathbf{1}}$ & $\boldsymbol{\Delta} \mathbf{t}_{\mathbf{1}-\mathbf{t}_{\mathbf{0}}}$ & $\mathbf{t}_{\mathbf{0}}$ & $\mathbf{t}_{\mathbf{1}}$ & $\boldsymbol{\Delta} \mathbf{t}_{\mathbf{1}-\mathbf{t}_{\mathbf{0}}}$ \\
\hline 5 & 9.4 & 9.2 & -0.2 & 6.70 & 6.70 & 0 & 1212.0 & 1284.0 & 72.0 \\
6 & 8.5 & 9.1 & 0.6 & 9.00 & 8.20 & -0.80 & 1066.0 & 1254.0 & 188.0 \\
7 & 9.0 & 8.7 & -0.3 & 4.26 & 3.94 & -0.32 & 694.5 & 929.0 & 234.5 \\
8 & 8.1 & 8.0 & -0.1 & 2.89 & 3.53 & 0.64 & 199.6 & 474.5 & 274.9 \\
9 & 8.7 & 8.4 & -0.3 & 8.25 & 6.56 & -1.69 & 186.7 & 393.3 & 206.6 \\
Mean & 8.7 & 8.7 & -0.1 & 6.22 & 5.79 & -0.43 & 671.8 & 867.0 & 195.2 \\
SD & 0.5 & 0.5 & 0.4 & 2.60 & 1.98 & 0.88 & 475.9 & 420.1 & 76.2 \\
\hline
\end{tabular}

Table V Serum levels and changes of b-ALP, TRAP5B, and DKK-1 in without-paricalcitol group

\begin{tabular}{cccccccccc}
\hline \multirow{2}{*}{ Patient } & \multicolumn{3}{c}{ b-ALP (U/L) } & \multicolumn{3}{c}{ TRAP5B (U/L) } & \multicolumn{3}{c}{ DKK-1 (pg/mL) } \\
\cline { 2 - 10 } & $\mathbf{t}_{\mathbf{0}}$ & $\mathbf{t}_{\mathbf{1}}$ & $\boldsymbol{\Delta} \mathbf{t}_{\mathbf{1}-\mathbf{t}_{\mathbf{0}}}$ & $\mathbf{t}_{\mathbf{0}}$ & $\mathbf{t}_{\mathbf{1}}$ & $\boldsymbol{\Delta} \mathbf{t}_{\mathbf{1}-\mathbf{t}_{\mathbf{0}}}$ & $\mathbf{t}_{\mathbf{0}}$ & $\mathbf{t}_{\mathbf{1}}$ & $\boldsymbol{\Delta} \mathbf{t}_{\mathbf{1}-\mathbf{t}_{\mathbf{0}}}$ \\
\hline 5 & 88.5 & 128.9 & 40.4 & 10.1 & 15.8 & 5.7 & 2061 & 1640 & -421 \\
6 & 52.4 & 79.3 & 26.9 & 4.8 & 7.0 & 2.2 & 3851 & 5928 & 2077 \\
7 & 61.5 & 54.0 & -7.5 & 3.1 & 6.7 & 3.6 & 1129 & 1776 & 647 \\
8 & 48.9 & 72.9 & 24.0 & 4.8 & 5.9 & 1.1 & 1622 & 1747 & 125 \\
9 & 19.2 & 29.7 & 10.5 & 1.6 & 3.6 & 2.0 & 1492 & 2037 & 545 \\
Mean & 54.1 & 73.0 & 18.9 & 4.9 & 7.9 & 2.9 & 2031 & 2626 & 595 \\
SD & 24.9 & 36.7 & 18.2 & 3.2 & 4.7 & 1.8 & 1071 & 1852 & 929 \\
\hline
\end{tabular}

iPTH: Intact parathyroid hormone;TRAP5b: Tartrate-resistant-acid-phosphatase 5b; b-ALP: Bone specific alkaline phosphatase; DKK1: Dickkopf-related protein $1 ; t_{0}$ : time before initiation of study; $t_{1}: 3$ months after initiation of study; $\Delta t_{1}-t_{0}$ : Change from $t_{0}$ to $t_{1}$

calcium and phosphate are diet intake and other therapies associated with CKD-MBD such as phosphate binder and bisphosphonate (KDIGO, 2009; NKF, 2013).

Phosphate binder used in this study is calcium and lanthanum based. The mechanism of phosphate binder is binding phosphate from food intake in intestine. The risk of hypercalcemia in calcium-based phosphate binder is higher than do lanthanum-based (Salusky, 2006). Meanwhile administration of biphosphonate such as risedronate will reduce bone resorption so that no caused by increasing level of calcium and phosphate (Martin, et al., 1998; Toussaint, et al.,
2009). In paricalcitol therapy there were 2 cases with increase level of iPTH level. This is due the paricalcitol doses have not optimal yet. In this study the evaluation of calcium, phosphate, iPTH, TRAP5b, b-ALP, and DKK-1 was done before initiation and after three months without dose titration of paricalcitol, so the $30 \%$ targeteddecrease iPTH was not achieved. According to the recommendation for doses titration of paricalcitol, dose is increased by $0.04 \mu \mathrm{g} / \mathrm{kg}$ (maximum $16.8 \mu \mathrm{g}$ ) to be adapted levels of iPTH and calcium periodically. If iPTH levels decrease $<30 \%$ and calcium $<11.5 \mathrm{mg} / \mathrm{dL}$, the paricalcitol dose should be increased (Lacy, et al., 2011; Martin, et al., 1998). 
The elevation of iPTH levels stimulates osteoclast reflected by the elevation of TRAP5b (Saliba and El-Haddad, 2009). This results were shown in case 1 and 2 -paricalcitol group, level of TRAP5b was still high. In case 4 the elevation of TRAP5b was influenced by the elevation of iPTH and also patient has a history hyperuricemia. In this condition level of TRAP5b increased (Zhao, et al., 2012).

Reduction level of iPTH serum is followed by decreasement of bone turnover (Martin, and Gonzales, 2007). Actually, in paricalcitol group two cases declined of b-ALP level although the iPTH level increased. This is due to the suppression effects of paricalcitol in osteoblast by $\mathrm{Wnt} / \beta$ catenin pathway, induced the inhibition in osteoblast proliferation and differentiation $(\mathrm{He}$, et al., 2011; Peterlik, and Cross, 2013). Meanwhile decreasement of b-ALP in one case (without paricalcitol group) is caused by risedronate therapy during the study. The similarity of chemical structure between risedronate and pyrophosphate is underlining the inhibition mechanism of bone matrix mineralization (propagation of hydroxyapatite crystal), and finally could suppres b-ALP levels (Nancollas, et al., 2006; Bilezikian, et al., 2008; Recker, et al., 2008).

Decreasement of activity stromal VDR due to calcitriol deficiency caused the elevation of DKK-1. Administration of paricalcitol was aimed to reduce DKK-1 by activation of VDR (Cianferotti, and Demay, 2007).

In case 3, after paricalcitol therapy the level of DKK1 increased, it may be caused by the elevation of uric acid (Zhao, et al., 2012). However, the elevation of uric acid is not always increase DKK-1 level, as in case 4. This is because of other factors such as risedronate which had effect in reducing DKK-1 (Memon, et al., 2013). Furthermore, in case 5 (without paricalcitol group) patient has history of gastro-esophageal reflux disease (GERD) with administration of cisapride that may reduce DKK-1 (Storr, et al., 2000; Lyrus, et al., 2014).

Figure 1-3 showed there were positive correlation between iPTH and b-ALP, TRAP5b, DKK-1. Figure 4 showed there was positive correlation beetwen TRAP5b and b-ALP Secondary hyperparathyroidism on CKD-MBD caused high turnover metabolic bone disease (Martin and Gonzales, 2007; Malluche, et al, 2012) and vascular calcification (Marinou, et al., 2012; Drueke and Massy, 2016) Characterization of high turnover metabolic bone disease begins with increased osteoclast activity and followed by increased activity of osteoblast (Dimkovic, 2001). Figure 5 and 6 showed no correlation between DKK-1 and TRAP5b; DKK-1 and b-ALP. This results maybe caused by level of DKK-1 is not only influenced by iPTH level but also by inflammation cytokines such as IL-6 and TNF- $\alpha$ (Cianferotti, and Demay, 2007; Yao, et al., 2011; Yeremenko, et al., 2015).

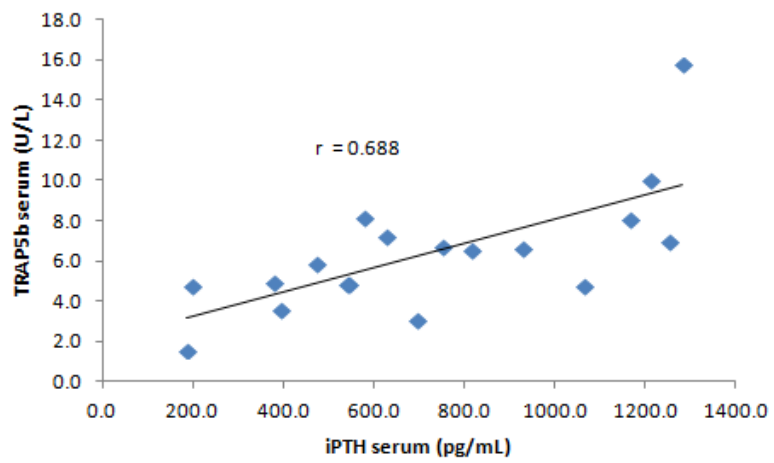

Figure 1. Correlation between serum level iPTH and TRAP5b

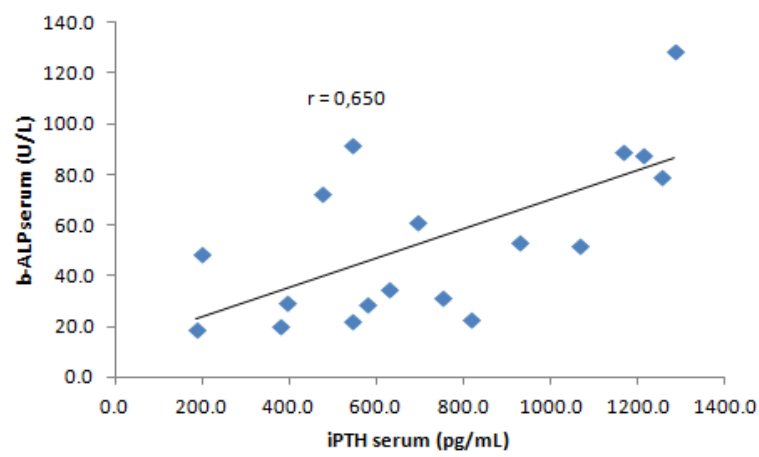

Figure 2. Correlation between serum level iPTH and b-ALP

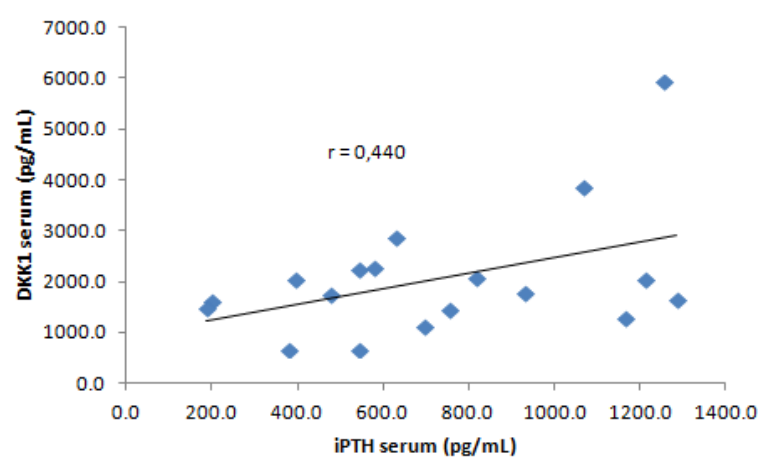

Figure 3. Correlation between serum level iPTH and DKK-1 


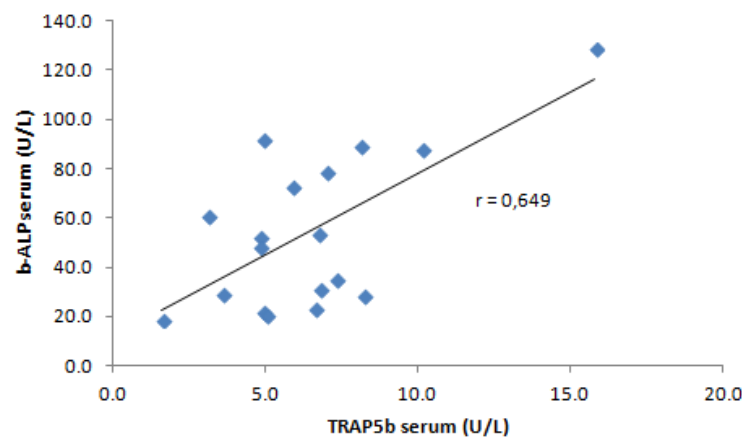

Figure 4. Correlation between serum level TRAP5b and $b$-ALP

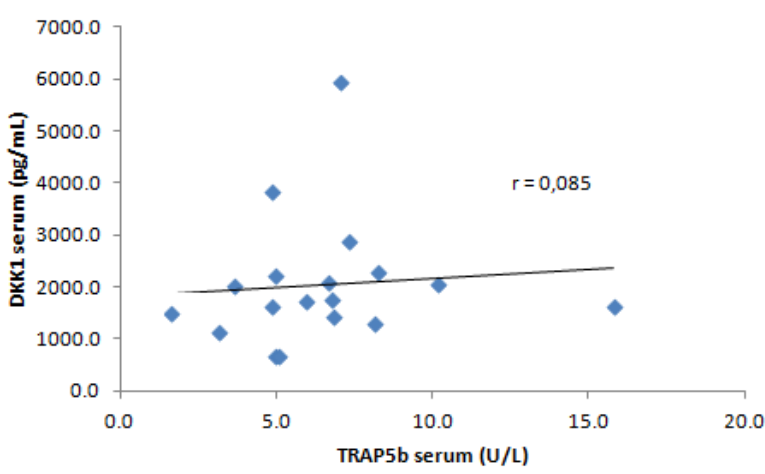

Figure 5. Correlation between serum level TRAP5b and DKK-1

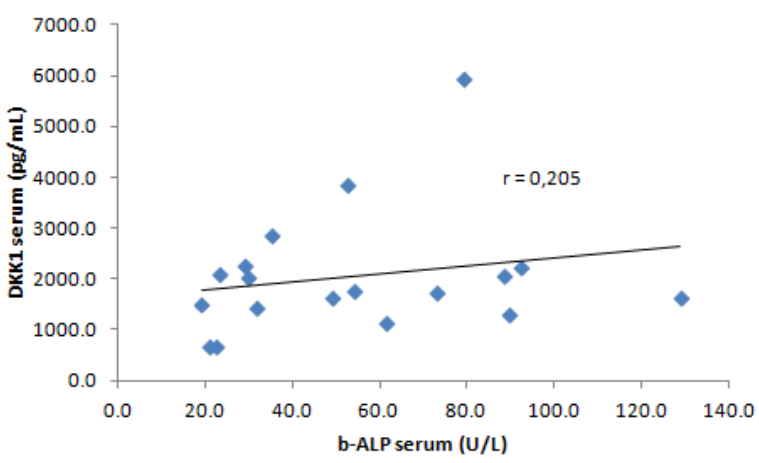

Figure 6. Correlation between serum level b-ALP and DKK-1

Of the overall results suggesting the use of paricalcitol suppresses iPTH increase without effecting an increase in serum calcium and phosphate. Paricalcitol administration decrease in marker bone turnover suppression b-ALP and TRAP5b, where in paricalcitol group there was a smaller increase TRAP5b compared to the group without paricalcitol. Paricalcitol decreased DKK- 1, a marker of vascular calcification.
The limitations of our study were variation of the patient's comorbid i.e diabetes mellitus type 2 and hypertension that can affect the result, variation of therapy regiment for CKD-MBD i.e phosphate binder and calcium supplement, variation of patient daily activity and food. To ensure these results are needed more samples.

\section{CONCLUSION}

The paricalcol administration suppresses the increase in iPTH level, bone turnover and vascular calcification showed by decreasing or supresses the increase b-ALP, TRAP5b, DKK-1 levels without increasing calcium and phosphate levels.

\section{REFERENCE}

Bilezikian JP., Raisz LG., and Martin TJ., 2008. Principles of Bone Biology $3^{\text {rd }}$ Edition. Academic Press, USA. 1543-1572

Cianferotti L., and Demay MB., 2007. VDR-Mediated Inhibition of DKK1 and SFRP2 Suppresses Adipogenic Differentiation of Murine Bone Marrow Stromal Cells. J Cell Biochem. 101: 8088

Coyne, D.W., Andress, D.L., Amdahi, M.J., Ritz E, de Zeeuw, 2013. Effects of paricalcitol on calcium and phosphate metabolism and markers of bone health in patients with diabetic nephropathy: results of the VITAL study, Nephrol. Dial. Transplant. ; 28: 2260- 2268.

Cozzolino M., Urena-Torres P., Vervloet MG., Brandenburg V, Bover J, Goldsmith D, Larsson TE, Massy ZA, Mazzaferro S, 2014. Is Chronic Kidney Disease - Mineral Bone Disorder (CKDMBD) Really A Syndrome ?, Nephrol. Dial. Transplant. 29: 1815-1820

Dimkovic, N., Oreopoulos, D.G., 2001. High and low turnover bone disease in patients on chronic peritoneal dialysis, Nephrol. Dial. Transplant. :16(Suppl 6):114-116.

Dipiro JT., Wells BG., Chisholm-Burns MA., Schwinghammer T, Wells B, Malone P, 2013. Pharmacotherapy Principles \& Practice Third Edition. Mc Graw Hill, USA: 467-500

Drueke, T.B. and Massy, Z.A., 2016. Changing bone patterns with progression of chronic kidney disease, Kidney International:89: 289-302

Fukugawa M., Yokoyama K., Koiwa F., Taniguchi M., Shoji T., et al., 2013. Clinical Practice Guideline for the Management of Chronic Kidney Disease-Mineral and Bone Disorder. J Jpn Soc Dial Ther. 17(3): 247-288

He W., Kang YS., Dai C., Liu Y., 2011. Blockade of Wnt/ $\beta$-Catenin Signaling by Paricalcitol 
Ameliorates Proteinuria and Kidney Injury. J Am Soc Nephrol. 2: 90-103

Jilka, RL, O'Brien, CA, Bartell, SM., Weinstein RS, Manolagas SC., 2010. Continuous Elevation of PTH Increases the Number of Osteoblasts via Both Osteoclast-Dependent and Independent Mechanisms. Journal of Bone and Mineral Research. 25(11):2427-2437.

Kidney Disease: Improving Global Outcomes (KDIGO) CKD-MBD Work Group, 2009. KDIGO clinical practice guideline for the diagnosis, evaluation, prevention, and treatment of chronic kidney disease-mineral and bone disorder (CKD-MBD). Kidney Int. 76(Suppl 113): S1-S130.

Lacy CF., Amstrong LL., Goldman MP., Lance LL., 2011. Drug Information Handbook 20 edition. Lexicomp, USA

Lee SB., and Kalluri R., 2010. Mechanistic connection between inflammation and fibrosis. Kidney Int. 78(Supp 119): 22-26

Llach F., Keshav G., Goldblat MV., Lindberg JS., Sadler R., Delmez J., Arruda J., Lau A, Slatopolsky E., 1998. Suppression of Parathyroid Hormone Secretion in Hemodialysis Patients by a Novel Vitamin D Analogue: 19-Nor-1,25-Dihydroxyvitamin D2. Am J Kidney Dis. 32(4) suppl 2: 48-54

Lyros O., Rafiee P., Nie L., Medda R, Jovanovic N, Schmidt J, Mackinnon A, Venu N, Shaker R, 2014. Dickkopf-1, the Wnt antagonist, is induced by acidic $\mathrm{pH}$ and mediates epithelial cellular senescence in human reflux esophagitis. Am J Physiol Gastrointest Liver Physiol. 306: 557-574

Malluche, HH., Porter, DS., Jameson, JL ,MonierFaugere MC., et al., 2012. Differences in Bone Quality in Low- and High- Turnover Renal Osteodystrophy, J. Am. Soc. Nephrol.:23(3):525-532.

Marinou K., Christodoulides C., Antoniades C., Koutsilieris M., 2012. Wnt signaling in cardiovascular physiology. Trends Endocrinol Metab. 23(12): 628-636

Martin KJ., and Gonzales EA., 2007. Metabolic Bone Disease in Chronic Kidney Disease, J. Am. Soc. Nephrol. 18: 875-885

Martin KJ., Gonzales EA., Gellens M.,Hamm LL., Abboud H., Lindberg J.. 1998. 19-Nor-1-a-25Dihydroxyvitamin D2 (Paricalcitol) Safely and Effectively Reduces the Levels of Intact Parathyroid Hormone in Patients on Hemodialysis. J Am Soc Nephrol 9: 1427-1432
Memon AR., Butler JS., O’Riordan MV.,Guerin E., Dimitrov BD., Harty JA., 2013. Comparison of Serum Dkk1 (Dickkopf-1) and Bone Mineral Density in Patients on Bisphosphonate Treatment VS no Treatment. J Clin Densitom. 16(1): 118-124

Nancollas GH., Tang R., Phipps RJ., Henneman Z, Gulde S, Wu W, Mangood A, Russell RG, Ebetino FH.., 2006. Novel insights into actions of bisphosphonates on bone: Differences in interactions with hydroxyapatite. Bone. 38: 617-627

National Kidney Foundation (NKF), 2013. Nutrition and Hemodialysis. NKF, New York

Peterlik M., Kallay E., and Cross HS., 2013. Calcium Nutrition and Extracellular Calcium Sensing: Relevance for the Pathogenesis of Osteoporosis, Cancer and Cardiovascular Diseases. Nutrients. 5:302-327.

Recker RR., Delmas PD., Halse J., Reid IR, Boonen S, García-Hernandez PA, Supronik J, Lewiecki EM, Ochoa L, Miller P, Hu H, Mesenbrink P, Hartl F, Gasser J, Eriksen EF. 2008. Effects of intravenous zoledronic acid once yearly on bone remodeling and bone structure. J. Bone. Miner. Res. 23: 6-16.

Saliba W., and El-Haddad B., 2009. Secondary Hyperparathyroidism: Pathophysiology and Treatment. J Am Board Farm Med. 22: 574-581

Salusky IB., 2006. A new era in phosphate binder therapy: What are the options?. Kidney Int. 70: 10-15

Shetty, S., Kapoor, N., Bondu, J.D., Shetty S, Kapoor N, Bondu JD, Thomas N, Paul TV., 2016. Bone turnover markers: Emerging tool in the management of osteoporosis, Indian J Endocrinol Metab. 20(6): 846-852.

Slatopolsky E., Finch J., and Brown A., 2003. New Vitamin D Analogs. Kidney Int. 63 (Suppl 85): 83-87

Storr M., Meining A., and Allescher HD., 2000. Pathophysiology and Pharmacological Treatment of Gastroesophageal Reflux Disease. Dig Dis. 18: 93-102

Toussaint ND., Elder GJ., and Kerr PG., 2009. Bisphosphonates in Chronic Kidney Disease; Balancing Potential Benefits and Adverse Effects on Bone and Soft Tissue. Clin J Am Soc Nephrol. 4: 221-233

Yao G., Wu J., Troiano N., Insogna K., 2011. Targeted Over-expression of Dkk1 in Osteoblasts Reduces Bone Mass But Does Not Impair the Anabolic Response to Intermittent PTH 
Treatment in Mice. J Bone Miner Metab. 29(2): 141-148

Yeremenko N., Zwerina K., Rigter G., Pots D, Fonseca JE, Zwerina J, Schett G, Baeten D 2015. Tumor Necrosis Factor and Interleukin-6 Differentially Regulate Dkk-1 in the Inflamed
Arthritic Joint. Arthritis Rheumatol. 67(8): 2071-2075

Zhao W., Gao H., Zhu JX., Zhang XW, Li ZG., 2012. Relation of serum Dickkopf-1 with bone destruction in patients with gouty arthritis. Beijing Da Xue Xue Bao. 44(2): 254-259 